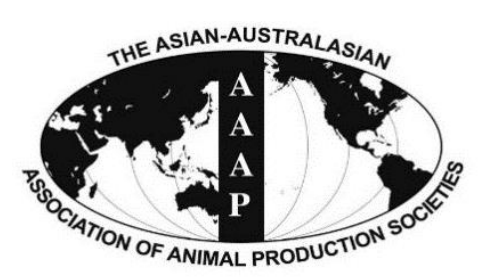

\title{
Resveratrol-loaded Nanoparticles Induce Antioxidant Activity against Oxidative Stress
}

\author{
Jae-Hwan Kima, Eun-Young Park ${ }^{\text {a }}$, Ho-Kyung Ha, Chan-Mi Jo, Won-Jae Lee, \\ Sung Sill Lee, and Jin Wook Kim* \\ Department of Animal Bioscience (Institute of Agriculture and Life Science), \\ Division of Applied Life Science (BK21 program), Gyeongsang National University, Jinju 660-701, Korea
}

\begin{abstract}
Resveratrol acts as a free radical scavenger and a potent antioxidant in the inhibition of numerous reactive oxygen species (ROS). The function of resveratrol and resveratrol-loaded nanoparticles in protecting human lung cancer cells (A549) against hydrogen peroxide was investigated in this study. The 2,2'-azino-bis(3-ethylbenzothiazoline-6-sulphonic acid (ABTS) assay was performed to evaluate the antioxidant properties. Resveratrol had substantially high antioxidant capacity (trolox equivalent antioxidant capacity value) compared to trolox and vitamin E since the concentration of resveratrol was more than $50 \mu \mathrm{M}$. Nanoparticles prepared from $\beta$-lactoglobulin $(\beta$-lg) were successfully developed. The $\beta$-lg nanoparticle showed 60 to $146 \mathrm{~nm}$ diameter in size with negatively charged surface. Non-cytotoxicity was observed in Caco- 2 cells treated with $\beta$-lg nanoparticles. Fluorescein isothiocynate-conjugated $\beta$ $\lg$ nanoparticles were identified into the cell membrane of Caco-2 cells, indicating that nanoparticles can be used as a delivery system. Hydrogen peroxide caused accumulation of ROS in a dose- and time-dependent manner. Resveratrol-loaded nanoparticles restored $\mathrm{H}_{2} \mathrm{O}_{2}$-induced ROS levels by induction of cellular uptake of resveratrol in A549 cells. Furthermore, resveratrol activated nuclear factor erythroid 2-related factor 2-Kelch ECH associating protein 1 (Nrf2-Keap1) signaling in A549 cells, thereby accumulation of Nrf2 abundance, as demonstrated by western blotting approach. Overall, these results may have implications for improvement of oxidative stress in treatment with nanoparticles as a biodegradable and non-toxic delivery carrier of bioactive compounds. (Key Words: Resveratrol, Nanoparticle, Oxidative Stress, $\beta$-Lactoglobulin, Caco-2 Cell)
\end{abstract}

\section{INTRODUCTION}

Resveratrol (3,5,4'-trihydroxy-trans-stilbene) is classified as a polyphenol, which is stilbene-based structure has two phenolic rings linked by a styrene double bond, and is found in various plants, especially in the skin of grapes, blueberries, and mulberries (Bravo, 1998; Seeram et al., 2006). It has been studied in antioxidant activities, antiinflammatory effects and pro-apoptic effects (de la Lastra and Villegas, 2005; 2007). In earlier studies, resveratrol was a major compound, which reduced an incidence of cardiovascular disease in certain groups with high-fat diet

\footnotetext{
* Corresponding Author: Jin Wook Kim. Tel: +82-55-772-1885, Fax: +82-55-772-1889, E-mail: jinkim@gnu.ac.kr

a Both of these authors contributed equally to this work.

Submitted Sept. 16, 2015; Revised Oct. 18, 2015; Accepted Nov. 30, 2015
}

intake and moderate consumption of red wine. This phenomenon is known as the French paradox (Renaud and de Lorgeril, 1992; Soleas et al., 1997; Ignatowicz and BaerDubowska, 2001).

The term reactive oxygen species (ROS) is used for short-lived diffusible entities such as hydroxyl, alkoxyl or peroxyl radicals and for some radical species of medium lifetime such as superoxide or nitroxyl radical (Beckman and Koppenol, 1996). Over the last few years, several studies have demonstrated the evidence of cellular function of ROS in mediating of oxidative stress. Excess ROS have destructive actions on both DNA and proteins which have been implicated in mutagenesis, oncogenesis and aging (Schieber and Chandel, 2014). Resveratrol is a free radical scavenger because of the redox properties of its phenolic hydroxyl groups and the potential for electron delocalization (Aggarwal et al., 2006). Resveratrol also has 
potent antioxidant activities due to its ability of induction of a variety of intracellular antioxidant enzymes (Schieber and Chandel, 2014). Resveratrol induces Nrf2 thought to be essential transcription factor for antioxidant enzymes. Nrf2 is a basic leucine zipper transcription factor, which is originally identified as a binding protein. Keap1 was demonstrated to regulate the intracellular localization of Nrf2. The dissociation of Nrf2 from Keap1 allows for nuclear accumulation of Nrf2 and enhances expression of its target cytoprotective genes encoding antioxidant enzymes such as $\mathrm{NAD}(\mathrm{P}) \mathrm{H}$ : quinone oxidoreductase 1 , glutathione S-transferases, heme oxygenase 1, and glutamate-cysteine ligase (Itoh et al, 1997;1999; Mates et al., 1999; Dinkova-Kostova et al., 2002).

Nanoparticles are collodial polymeric delivery systems that have the size from 1 to $200 \mathrm{~nm}$. Due to subcellular size, nanoparticles can improve the bioavailability of bioactive compounds, particularly hydrophobic bioactive compounds (Cheng et al., 2006). Our previous study showed that nanoparticle prepared from $\beta$-lactoglobulin $(\beta$-lg), one of major components in whey proteins has a great potential for application to delivery system due to its generally regarded as safe (GRAS) status, biodegradable property and structure-forming capability (Chen and Subirade, 2005; Livney, 2010; Ha et al., 2015).

The objectives of this study were to determine antioxidant activity of resveratrol-loaded nanoparticles. First, the antioxidant capacity of resveratrol was measured by 2,2'-azino-bis(3-ethylbenzothiazoline-6-sulphonic acid) (ABTS) assay. Second, the optimal conditions (incubation time and concentration) to generate ROS from hydrogen peroxide in A549 cells were analyzed. Third, Physicochemical properties, cytotoxicity and cellular uptake of nanoparticle produced from $\beta$-lg was evaluated. Fourth, the antioxidant activity of resveratrol-loaded nanoparticle and its cellular signaling were determined.

\section{MATERIALS AND METHODS}

\section{Cell culture condition}

Human type-2 alveolar epithelial cell (A549) was purchased from American Type Culture Collection and maintained in continuous culture at $37^{\circ} \mathrm{C}$ in a $5 \% \quad \mathrm{CO}_{2}$ atmosphere in RPMI 1640 containing $1 \%$ penicillinstreptomycin and $10 \%$ fetal bovine serum (FBS). Human colon epithelial cell (Caco-2) was purchased from American Type Culture Collection and maintained in continuous culture at $37^{\circ} \mathrm{C}$ in a $5 \% \mathrm{CO}_{2}$ atmosphere in Dulbecco's Modified Eagle's medium (DMEM) containing $1 \%$ penicillin (streptomycin) and 10\% FBS.

\section{Experimental design and treatment}

A549 cells were seeded in six well plates containing culture medium supplemented with $10 \%$ FBS in a total volume of $10 \mathrm{~mL}$. After the cells were grown to $80 \%$ to $90 \%$ confluency, they were maintained in culture medium supplemented with $1 \%$ FBS for $3 \mathrm{~h}$. All treatments were performed in triplicate. The cells were pre-treated with 50 $\mu \mathrm{M}$ of resveratrol in $0.5 \%$ dimethyl sulfoxide (DMSO) for $4 \mathrm{~h}$ at $37^{\circ} \mathrm{C}$ in a $5 \% \mathrm{CO}_{2}$ atmosphere and then treated with $\mathrm{H}_{2} \mathrm{O}_{2}$ (50 to $1,000 \mu \mathrm{M}$ ) with or without resveratrol for $0.5,1$, $2,3,8,16$, and $24 \mathrm{~h}$ at $37^{\circ} \mathrm{C}$.

\section{Measurement of antioxidant capacity}

2,2'-azino-bis(3-ethylbenzothiazoline-6-sulphonic acid) (ABTS, Sigma-Aldrich, ST Louis, MO, USA) was dissolved in water to make a final $7 \mathrm{mM}$ concentration. ABTS radical cation was produced a reacting ABTS stock solution with $2.45 \mathrm{mM}$ potassium persulfate standing on the dark at room temperature for $24 \mathrm{~h}$. The ABTS solution was diluted with ethanol at absorbance of $0.7 \mathrm{~nm}$. And then mixed by adding $0.1 \mathrm{~mL}$ of the antioxidant solutions (resveratrol (trans-3,4,5-trihydroxystilbene), Vitamin E and trolox, Sigma-Aldrich, USA) to make the reaction mixtures in a final volume of $1 \mathrm{~mL}$. The reaction mixtures were shaken vigorously and kept in the dark for 6 min at $37^{\circ} \mathrm{C}$. The absorbance of the remaining ABTS radical cation was determined at $734 \mathrm{~nm}$ by spectrophotometer (Genesys10-S, Thermo, Inc., Hudson, NH, USA). Trolox equivalent antioxidant capacity (TEAC, $\mu \mathrm{M}$ trolox equivalent to each antioxidant) values were calculated by the equation (difference of sample absorbance $[\Delta$ sample abs]/difference of trolox absorbance $[\Delta$ trolox abs]).

\section{Measurement of reactive oxygen species}

ROS release was determined using 5-(and-6)chloromethyl-2',7' dichlorodihydrofluorescein diacetate ( $\mathrm{H}_{2}$ DCFDA, Sigma-Aldrich, USA) which is an oxidantsensitive fluorescent probe. Inside the cell, the probe is deacetylated by esterases and formed $\mathrm{H}_{2} \mathrm{DCF}$ which is oxidized by ROS to 2',7' dichlorofluorescein (DCF), highly fluorescent compound. A549 cells were seeded in 6-well plates in a total final volume of $3 \mathrm{~mL}$ and pre-treated with or without resveratrol $(50 \mu \mathrm{M})$ for $4 \mathrm{~h}$ and then treated with $\mathrm{H}_{2} \mathrm{O}_{2}$ (400 and 1,000 $\mu \mathrm{M}$, respectively) for $2 \mathrm{~h}$. Following the treatments, the culture medium was removed, the cells were washed with phosphate-buffered saline (PBS) and incubated with $\mathrm{H}_{2}$ DCFDA $(10 \mu \mathrm{M})$ at $37^{\circ} \mathrm{C}$ for $30 \mathrm{~min}$. Cells were then trypsinized, washed and resuspended in PBS. The population of live cells was measured by FACSCaliur flow cytometry and Cellquest Pro Software (Becton Dickenson, Bedford, MA, USA).

\section{Preparation of beta-lactoglobulin nanoparticle and its} conjugation with fluorescein isothiocynate

$\beta$-lg nanoparticles were manufactured by a modified 
ionic gelation method described in $\mathrm{Ha}$ et al. (2015). To prepared $\beta$-lg nanoparticles containing resveratrol, $100 \mu \mathrm{L}$ of $5 \mathrm{mM}$ resveratrol dissolved in ethanol was mixed with $9.9 \mathrm{~mL}$ of $\beta$-lg solution $(1 \%$, w/v). Final concentration of resveratrol was $50 \mu \mathrm{M}$. $4 \mathrm{mM} \mathrm{CaCl} \mathrm{Ca}_{2}$ was added to resveratrol $/ \beta$-lg mixture and then adjusted to $\mathrm{pH} 9.5$ using $0.1 \mathrm{M} \mathrm{NaOH}$. The mixture was stirred for $30 \mathrm{~min}$, heated at $65^{\circ} \mathrm{C}$ for 10 min using a water bath (Wisecircu, Daihan Scientific, Inc., Seoul, Korea), and cooled to room temperature on ice-water. To produce fluorescein isothiocynate (FITC)-conjugated $\beta$-lg, $0.1 \mathrm{~mL}$ of FITC dissolved in ethanol $(40 \mathrm{mg} / \mathrm{mL})$ was mixed with $10 \mathrm{~mL}$ of $1 \%(\mathrm{w} / \mathrm{v}) \beta$-lg solution in $0.1 \mathrm{M}$ carbonate buffer $(\mathrm{pH} 9.0)$. FITC $/ \beta$-lg mixture was stirred for $2 \mathrm{~h}$ in a dark room to form FITC-conjugated $\beta$-lg. Unreacted FITC was removed by dialysis against distilled water for $48 \mathrm{~h}$ using a dialysis membrane (3.5 kDa MW cut-off, Thermo Scientific, USA) in a dark room. The dialyzed mixture was freeze-dried and FITC-conjugated $\beta$-lg was obtained. FITC-conjugated $\beta$-lg nanoparticles were prepared with $1 \%(\mathrm{w} / \mathrm{v})$ FITCconjugated $\beta$-lg. The remaining steps were followed as described above.

Morphologies of $\beta$-lg nanoparticles were observed using a transmission electron microscopy (TEM, FEI Tecnai 12, Philips, Eindhoven, Netherlands). $\beta$-lg nanoparticle suspension was 10 -fold diluted with deionized water and 20 $\mu \mathrm{L}$ of suspension was placed into a 200 mesh copper grid coated with carbon. Nanoparticles on a grid were negatively stained using $2 \%$ uranyl acetate solution for $15 \mathrm{~s}$ followed by air-dry at room temperature. TEM images of $\beta$-lg nanoparticle were obtained with an operating voltage of 120 kV. Zetasizer Nano ZS (Malvern Instruments, Malvern, UK) was used to investigate the particle size (mean particle diameter, Z-average) and zeta-potential value of $\beta$ - $\lg$ nanoparticles. Nanoparticle suspension was 10 -fold diluted with deionized water and particle size and zeta-potential value were determined at room temperature with scattering angles of $90^{\circ}$ and $20^{\circ}$, respectively.

\section{Cell cytotoxicity and cellular uptake of $\beta$-lg nanoparticles}

Caco-2 cells seeded in 6-well plates were incubated at $37^{\circ} \mathrm{C}$ for $24 \mathrm{~h}$ using $5 \% \mathrm{CO}_{2}$ incubator for the formation of confluent layer. Culture medium replaced with serum-free DMEM was kept at $37^{\circ} \mathrm{C}$ for $30 \mathrm{~min}$. FITC-conjugated $\beta$-lg nanoparticles were dissolved in serum-free DMEM and then were added to Caco-2 cells following incubation at $37^{\circ} \mathrm{C}$ for $4 \mathrm{~h}$. Final concentration of $\beta$-lg nanoparticles was $50 \mu \mathrm{g} / \mathrm{mL}$. Cell cytotoxicity was measured by FACSCalbur flow cytometry and Cellquest Pro Software (BD Biosciences, Bedford, MA, USA). Cellular uptake was evaluated by using fluorescent microscopy (Leica DM 2500, Switzerland).

\section{Western blotting analysis}

A549 cells were lysed by protein extraction solution about $70 \mu \mathrm{L}$ (iNtron Biotechnology, Seoungnam, Korea). The protein concentrations of samples were determined through the bicinchoninic acid (BCA) assay kit (iNtron Biotechnology, Korea). A $30 \mu \mathrm{g}$ of protein were separated using $10 \%$ sodium dodecyl sulfate-polyacrylamide gel electrophoresis (SDS-PAGE). The gels were electrophoresed for $5 \mathrm{~h}(60 \mathrm{~mA})$ at room temperature and then transferred onto a nitrocellulose blotting membrane (Bio-rad, Hercules, CA, USA) for overnight. The membrane was blocked with 5\% skim milk in tris-buffered saline (TBS) with $0.01 \%$ Tween-20 for $1 \mathrm{~h}$ and incubated with rabbit polyclonal anti-Nrf2 antibody (1:250 dilution, Santa cruz, sc-13032, Dallas, TX, USA) or goat polyclonal anti-keap1 antibody (1:300 dilution Santa cruz, sc-15246, USA) for overnight. To detect Nrf2, keap1, Horseradish peroxidase-conjugated anti-rabbit $\operatorname{IgG}$ or anti-goat $\operatorname{IgG}$ (both at 1:5,000 dilution, KPL, Gaitherburg, MD, USA) were incubated as a secondary antibody for $1 \mathrm{~h}$ at room temperature. Immunoreactivity was visualized by an enhanced chemiluminescence detection kit (iNtron Biotechnology, Korea).

\section{Statistical analysis}

All data were addressed as mean \pm standard errors. The significance of effects for TEAC capacity of antioxidants was analyzed by a two-way analysis of variance (ANOVA) with Bonferroni post-test. The scavenging activities of antioxidants were estimated by linear regression method. Cytotoxicity, ROS production and ROS inhibition were analyzed by t-test and one-way ANOVA with the Fisher's least significant difference (LSD) test. All statistical analyses were used with SAS software package (SAS, 2003) and Graphpad Prism software (Version 5.0, Graphpad software, San Diego, CA, USA).

\section{RESULTS AND DISCUSSION}

\section{Antioxidant capacity of resveratrol}

ABTS assay was performed to investigate the antioxidant effect of resveratrol, and it showed that resveratrol had substantially high antioxidant effect (Figure 1A) compared to trolox and vitamin E. The antioxidant activity of resveratrol was measured by ABTS assay, based on interaction between resveratrol and $\mathrm{ABTS}^{\circ+}$. To investigate the ability of resveratrol to scavenge $\mathrm{ABTS}^{++}$ radical cation which has specific color showing maximum at $734 \mathrm{~nm}$, it was compared to standard trolox (Re et al., 1999) and vitamin E. The interaction with each sample and standard trolox showed the decreased absorbance of the $\mathrm{ABTS}^{++}$radical cation, and the result was expressed as percentage of scavenging activity of absorbance (Figure 
(A)

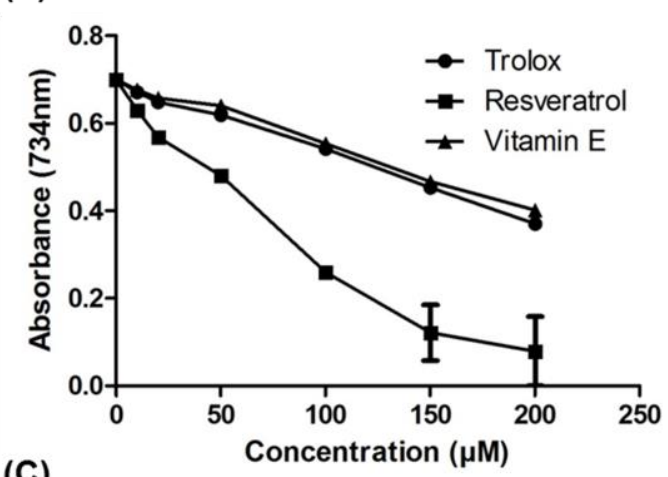

(C)

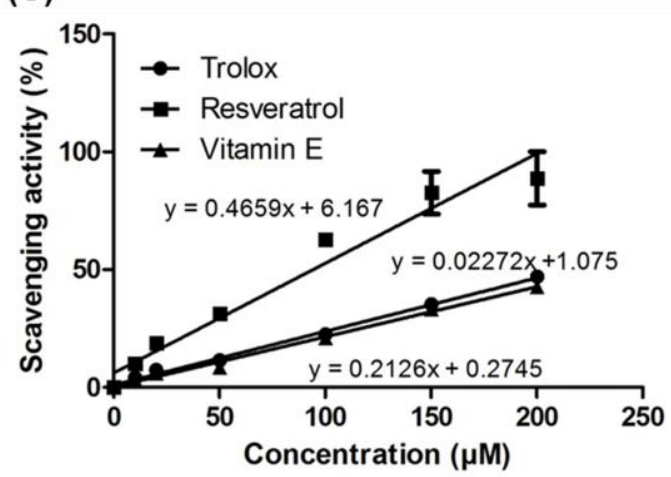

(B)

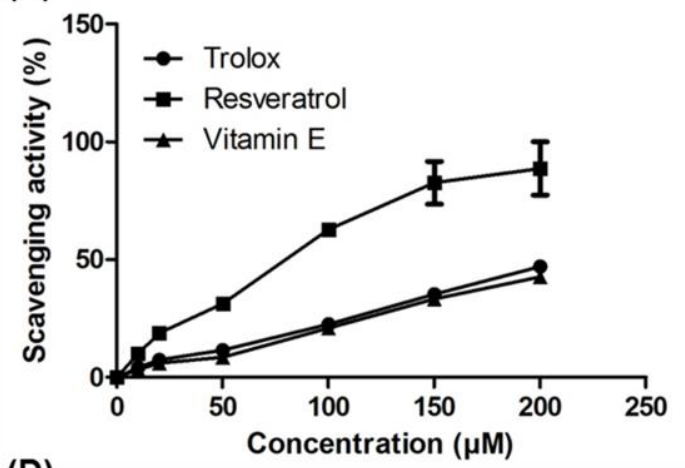

(D)

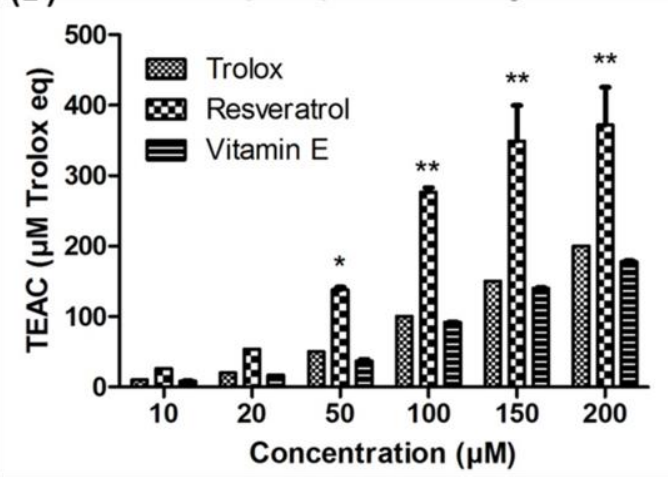

Figure 1. Evaluation of antioxidant capacity for resveratrol by 2,2'-azino-bis(3-ethylbenzothiazoline-6-sulphonic acid (ABTS) assay. (A) Absorbance (734 nm) variation of antioxidants, (B) Scavenging activity (\%) of antioxidants, (C) Linear regression analysis of scavenging activity, (D) Trolox equivalent antioxidant capacity (TEAC) values of resveratrol compared to standard (trolox) and vitamin E. Values represented means \pm standard error of the mean, by repeated-measured two-way analysis of variance with Bonferroni post-test. The different superscripts within each concentration were significantly different at $* \mathrm{p}<0.01$, ** $\mathrm{p}<0.001$.

1B).

The scavenging activities of trolox, vitamin $\mathrm{E}$ and resveratrol were increased with the treatment of higher concentration of each sample. The percent of inhibition was calculated as follows: Scavenging activity $(\%)=$ ([Absorbance ${ }_{734} \mathrm{~nm}$ of control - Absorbance $_{734} \mathrm{~nm}$ of sample) $\left.)\right] \div$ Absorbance $_{734} \mathrm{~nm}$ of control $) \times 100$. The $\mathrm{x}$-axis represented the concentration $(\mu \mathrm{M})$ and the $\mathrm{y}$-axis represented the scavenging effect. Trolox and vitamin $\mathrm{E}$ were shown similar plots, indicating that there were no significant differences in the scavenging activity of $\mathrm{ABTS}^{++}$radical cations. In the case of resveratrol, it had more antioxidant activity than other samples. When treated over $50 \mu \mathrm{M}$ of resveratrol, the ability to scavenge $\mathrm{ABTS}^{++}$radical cations was increased significantly $(\mathrm{p}<0.001)$. Figure $1 \mathrm{C}$ was represented by the linear regression of the scavenging effect. Each reaction kinetic plot was expressed by following the equations: trolox, $\mathrm{y}=0.2272 \mathrm{x}+1.075\left(\mathrm{R}^{2}=0.9939\right)$, vitamin $\mathrm{E}, \mathrm{y}=$ $0.2126 x+0.2745\left(R^{2}=0.9921\right)$, and resveratrol, $y=0.4659 x$ $+6.167\left(R^{2}=0.9932\right)$.

Trolox equivalent is used to provide the antioxidant capacity of each sample (Ou et al., 2001). The TEAC which is a simple, speedy, and reliable method for antioxidant activity has been used (Herraiz and Galisteo, 2004). The
TEAC values of each antioxidant were shown in Figure 1D. It showed that the antioxidant capacity was $25.93 \mu \mathrm{M}$ of resveratrol and $8.51 \mu \mathrm{M}$ of vitamin $\mathrm{E}$ per $10 \mu \mathrm{M}$ of trolox. In the case of $20 \mu \mathrm{M}$ of trolox, each sample was increased around two times. TEAC values were $138.12 \mu \mathrm{M}$ of resveratrol and $37.38 \mu \mathrm{M}$ of vitamin E per $50 \mu \mathrm{M}$ of trolox. In the values of TEAC were increased 276.92, 349.50, and $371.71 \mu \mathrm{M}$ of resveratrol per 100,150 , and $200 \mu \mathrm{M}$ of trolox, respectively. There were no significant differences between vitamin $\mathrm{E}$ and trolox by Bonferroni post-test. These results indicated that the antioxidative activity of resveratrol (over $50 \mu \mathrm{M}$ ) was significantly higher than that of trolox, and this $50 \mu \mathrm{M}$ of resveratrol was used for further experiments.

\section{Cytotoxicity and cellular uptake of $\boldsymbol{\beta}$-lg nanoparticle}

$\beta$-lg nanoparticle was used as a delivery system for resveratrol. For the application of bioactive compounds to functional foods, all materials used for the preparation of nanoparticle should be GRAS condition. Physiochemical properties of $\beta$-lg nanoparticles were evaluated by using a transmission electron microscope (TEM) and particle size analyzer. In TEM micrographs, spherical shapes of nanoparticles ranged in diameter from 60 to $146 \mathrm{~nm}$ were 
observed, indicating that nanoparticles were successfully formed (Figure 2A). The variation of size may be due to amounts of $\beta$-lg involved in formation of nano-structure by ionic and hydrophobic strength. The similar reports indicated that the size of whey protein particles was increased from 70 to $200 \mathrm{~nm}$ (Gracia-Julia et al., 2008) or from 97 to $176 \mathrm{~nm}$ (Ha et al., 2015) as heating temperature was increased. Negative zeta-potential value was $-16.0 \pm 1.8$, which indicated that nanoparticle had negative surface charges. Encapsulation efficiency of resveratrol was $96.9 \% \pm 0.2 \%$.

Several reports indicate that the small size of nanoparticles may cause toxicity problem, because a reduction in nanoparticle size increases the interactions between nanoparticles and cell membrane. Consequently, these interactions may induce the transient perforation of cell membrane which can cause the cytotoxicity (Yin et al., 2005; Zhang et al., 2008; Napierska et al., 2009; Cockburn et al., 2012). To investigate the cytotoxicity and cellular

(A)

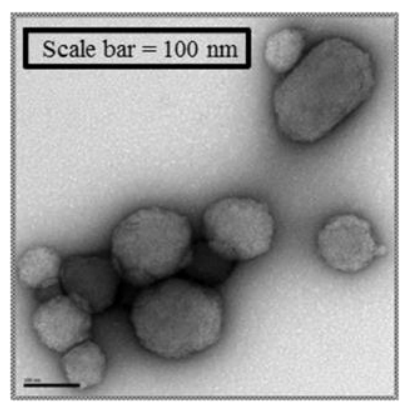

(C)

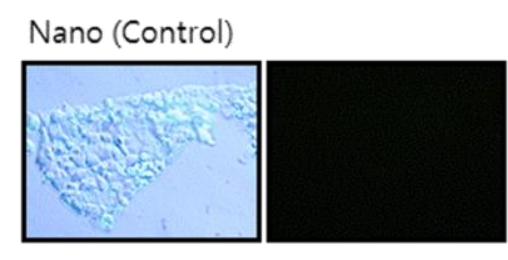

Nano-FITC

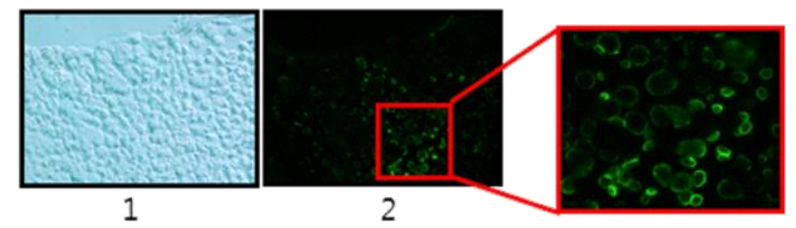

Figure 2. The characteristics of nanoparticle. (A) The morphologies of $\beta$-lactoglobulin nanoparticles were determined by a transmission electron microscope. (B) Caco-2 cells were incubated with nanoparticles (250 $\mu \mathrm{g} / \mathrm{mL})$ for $4 \mathrm{~h}$. Cytotoxicity was measured by FACSCaliur flow cytometry and Cellquest Pro Software (Becton Dickenson, Bredford, MA, USA). The statistical analysis was performed by t-test. NS, non-significant difference at $\mathrm{p}<0.05$. (C) FITC-conjugated nanoparticles were prepared by dialysis method. Cellular uptake of nanoparticles on Caco- 2 cell for $4 \mathrm{~h}$ incubation were evaluated by using optical (lane 1) and fluorescent microscopy (lane 2). FITC, fluorescein isothiocynate. uptake of nanoparticles, Caco-2 cells, derived from human colon epithelial cell, spontaneously differentiates in culture to form confluent monolayers with remarkable morphological and biochemical similarity to the small intestinal epithelium. Therefore, the uptake studies of nanoparticles observed in Caco- 2 cells could probably be considered to correlate with in vivo situation (Hidalgo et al., 1989). The cytotoxicity was determined by measuring the cell survival rate. Caco-2 cells were treated with nanoparticles conjugated with FITC for $4 \mathrm{~h}$. Nanoparticle $(250 \mu \mathrm{g} / \mathrm{mL})$ did not significantly $(\mathrm{p}<0.05)$ affect the cell survival rate (Figure 2B). Other nanoparticles prepared from food-grade compounds showed similar results. Oleylchitosan nanoparticle on A549 cells (Zhang et al., 2008) and chitosan-caseinophosphopeptide nanoparticles on Caco-2 cells were non-cytotoxic (Hu et al., 2012).

The cellular uptake of nanoparticles was evaluated by the fluorescent-based analysis (Win and Feng 2005; Powell et al., 2010). The FITC was used as a fluorescent marker to
(B)
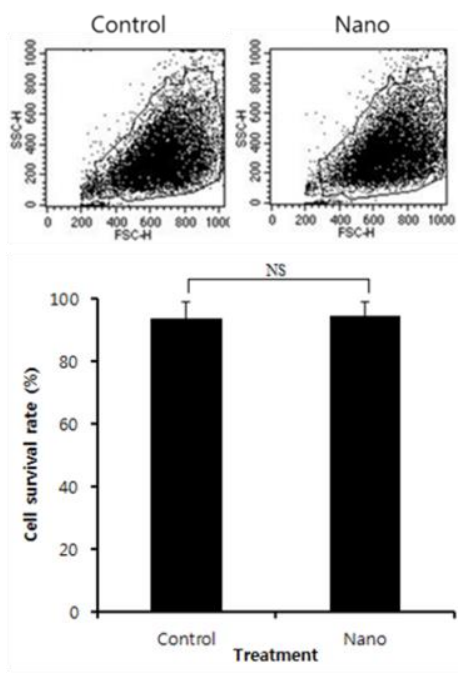
investigate the cellular uptake of nanoparticles in Caco-2 cells. FITC-conjugated nanoparticle (Nano-FITC) was identified into the membrane of Caco- 2 cells (Figure 2C). This result showed that $\beta$-lg nanoparticles were successfully absorbed by Caco- 2 cells. No fluorescence was observed in control (Nano) indicating that Caco-2 cell or $\beta$-lg nanoparticles did not have autofluorescence.

\section{ROS generation and its inhibition by resveratrol in A549 cells}

The excess production of ROS causes cell damage leading to cell death. To determine production of ROS in cells, 2', 7'-Dichlorofluorescin diacetate ( $\left.\mathrm{H}_{2} \mathrm{DCFDA}\right)$ assay was carried out to detect intracellular ROS. DCFDA has been used for detection of ROS by fluorescence microscopy or flow cytometry. This dye is non-fluorescent, but it becomes fluorescent when after cellular oxidation and elimination of acetate groups by cellular esterases (Hanakova et al., 2014). To clarify the antioxidant effect of resveratrol, hydrogen peroxide $\left(\mathrm{H}_{2} \mathrm{O}_{2}\right)$ treated to provide a similar condition for oxidative stress. A549 cells were treated with different concentration of $\mathrm{H}_{2} \mathrm{O}_{2}$, and it showed a dose-dependent increase in the level of ROS (Figure 3). An increase in DCF fluorescence was detected when after exposure of A549 cells to $200 \mu \mathrm{M}$ of $\mathrm{H}_{2} \mathrm{O}_{2}$ for $8 \mathrm{~h}$. DCF fluorescence was also increased when treatment with 400 and $1,000 \mu \mathrm{M}$ of $\mathrm{H}_{2} \mathrm{O}_{2}$ (Figure $3 \mathrm{~A}$ ). Fluorescence variation was expressed as percentage of measurement $(\mathrm{M})$ value for stressed cells (Figure 3B). There were no significant differences up to $100 \mu \mathrm{M}$ of $\mathrm{H}_{2} \mathrm{O}_{2}$, which means that these cells had not been affected by oxidative stress. A549 cells were exposed over $200 \mu \mathrm{M}$ of $\mathrm{H}_{2} \mathrm{O}_{2}$ for $8 \mathrm{~h}$, and the $\mathrm{M}$ value was increased significantly $(\mathrm{p}<0.05)$. There were significant differences between 200 and 400 to $1,000 \mu \mathrm{M}$ $(\mathrm{p}<0.05)$, while there were no significant differences between 400 and $1,000 \mu \mathrm{M}$ of $\mathrm{H}_{2} \mathrm{O}_{2}$. It was indicated that the level of ROS in stressed cells (over $200 \mu \mathrm{M}$ of $\mathrm{H}_{2} \mathrm{O}_{2}$ ) was three-fold more than in non-stressed cells ( 0 to $100 \mu \mathrm{M}$ of $\mathrm{H}_{2} \mathrm{O}_{2}$ ).

Time-dependent ROS generation by $\mathrm{H}_{2} \mathrm{O}_{2}$ was shown in Figure 4. The percentage of ROS release within a population of cells was demonstrated by the shift of peak to M1 zone. A549 cells were treated with 0, 400, and 1,000 $\mu \mathrm{M}$ of $\mathrm{H}_{2} \mathrm{O}_{2}$ for different time periods. There was a significant increase in the DCF fluorescence for at least $8 \mathrm{~h}$ following treatment (Figure 4A). Treatment with each concentration to A549 cells had little or no effect on intracellular oxidation from 0.5 to $3 \mathrm{~h}$. A concentration range $(0,400,1,000 \mu \mathrm{M})$ of $\mathrm{H}_{2} \mathrm{O}_{2}$ was compared in a timedependent manner, and it was expressed as the percentage of $\mathrm{M}$ value shown in Figure 4B. Intracellular ROS release did not significantly differ from 0.5 to $3 \mathrm{~h}$ of incubation with $\mathrm{H}_{2} \mathrm{O}_{2} \quad(\mathrm{p}<0.05)$. Treatments of $\mathrm{H}_{2} \mathrm{O}_{2}$ concentration

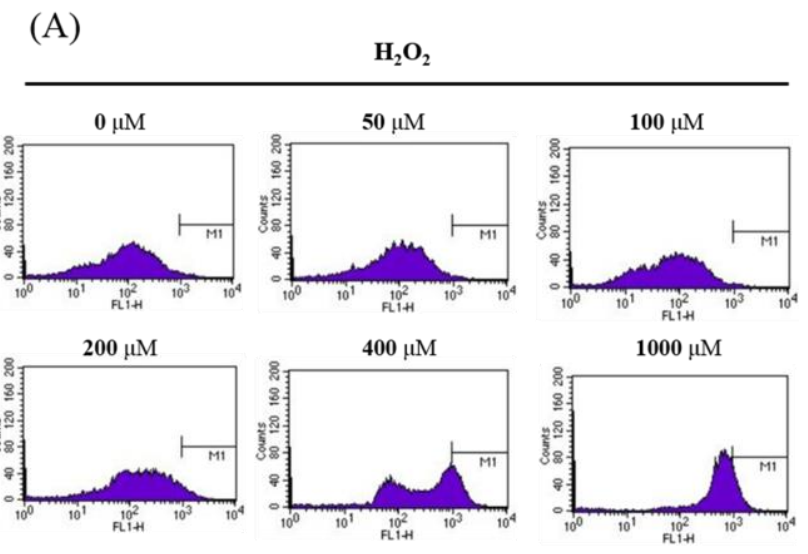

(B)

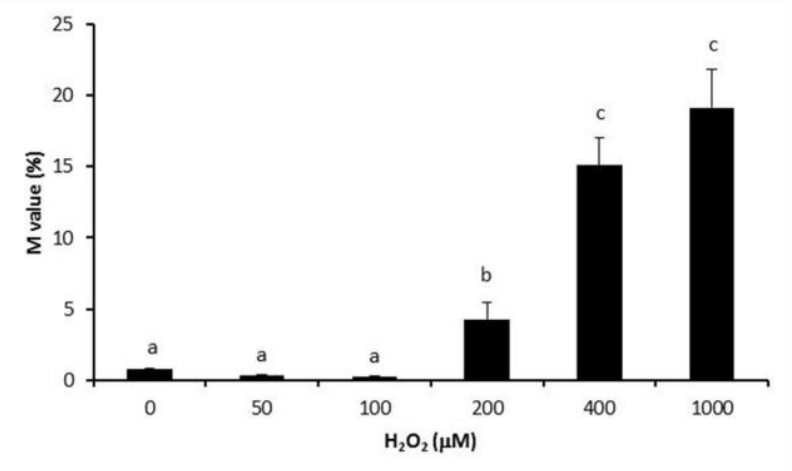

Figure 3. Dose-dependent reactive oxygen species (ROS) production by hydrogen peroxide. (A) A549 cells were treated with hydrogen peroxide for $8 \mathrm{~h}$. ROS release was determined by oxidized $\mathrm{H}_{2}$ DCFDA (DCF), which is an oxidant-sensitive fluorescent probe. (B) 2',7' Dichlorofluorescein (DCF) at each concentration was measured by FACSCaliur flow cytometry and was analyzed by one-way analysis of variance with least significant difference (LSD) multiple comparison method. The different alphabetical letters between hydrogen peroxide concentrations were significantly different at $\mathrm{p}<0.05$.

between 400 and $1,000 \mu \mathrm{M}$ were not different significantly for 8 and $16 \mathrm{~h}$, but there was a significant difference compared to control $(\mathrm{p}<0.05)$. However, the $\mathrm{M}$ value at $24 \mathrm{~h}$ incubation showed less than $12 \mathrm{~h}$ incubation, and significant differences in each $\mathrm{H}_{2} \mathrm{O}_{2}$ concentration $(\mathrm{p}<0.05)$. Therefore, the optimal concentration of $\mathrm{H}_{2} \mathrm{O}_{2}$ and treatment time period were $400 \mu \mathrm{M}$ and $8 \mathrm{~h}$, respectively.

A549 cells were pretreated with or without nanoparticles (Nano), resveratrol (Res), and resveratrolloaded nanoparticle (ResN) for $4 \mathrm{~h}$, followed by incubation with $400 \mu \mathrm{M}$ of $\mathrm{H}_{2} \mathrm{O}_{2}$ for $8 \mathrm{~h}$ (Figure 5A). Negative control was non-treated $\mathrm{H}_{2} \mathrm{O}_{2}$ to the cells, and $\mathrm{H}_{2} \mathrm{O}_{2}(400 \mu \mathrm{M})$ treated cells were used as a positive control to compare with each group of the level of ROS. The each peak of control and nanoparticle without Res was shifted to M1 zone after $\mathrm{H}_{2} \mathrm{O}_{2}$ treatment, while that of Res and ResN-treated groups was not shifted. Generation of ROS at each treatment was 

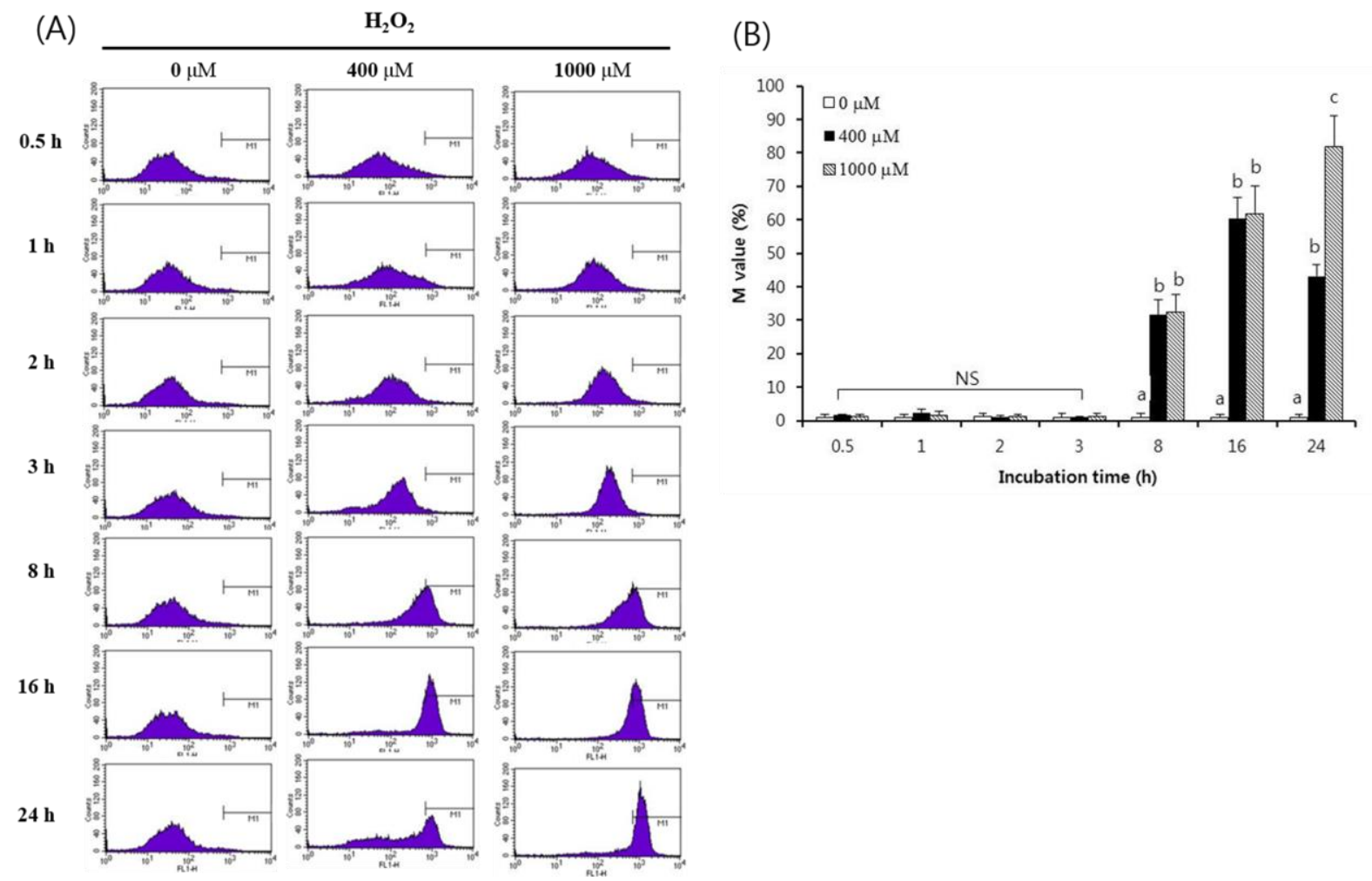

Figure 4. Time-dependent reactive oxygen species (ROS) production by hydrogen peroxide. (A) A549 cells were treated with hydrogen peroxide in a time dependent manner. ROS release was determined by oxidized $\mathrm{H}_{2}$ DCFDA (DCF), which is an oxidant-sensitive fluorescent probe. (B) 2',7' Dichlorofluorescein (DCF) at each incubation time was measured by FACSCaliur flow cytometry and was analyzed by two-way analysis of variance with least significant difference (LSD) multiple comparison method. The different alphabetical letters within incubation time were significantly different at $\mathrm{p}<0.05$. NS, non-significant difference at $\mathrm{p}<0.05$.

represented as percentage $M$ value, as shown in Figure 5B. There was a significant difference in treatment with or without $\mathrm{H}_{2} \mathrm{O}_{2}(\mathrm{p}<0.05)$. It was shown that the $\mathrm{M}$ values between non-loaded nanoparticle group and positive control group were not different significantly. It was indicated that non-loaded nanoparticle group had not effect on the formation of intracellular ROS. The M values treated with Res group and with ResN group were low as below 20\%, indicating that resveratrol had antioxidant activity. Moreover, the $\mathrm{M}$ value of ResN group was significantly lower than Res group. These results indicated that ResN had higher antioxidant effect than Res when treated to cells, and Nanoparticles might increase a cellular uptake of resveratrol. Previous studies have been shown the antioxidant activity of resveratrol. Zheng et al. (2010) observed that Res reduced intracellular ROS generation in human lens epithelial cell (HLEB-3). Cells were pretreated in the presence or absence of resveratrol $(20 \mu \mathrm{M})$ for $12 \mathrm{~h}$ prior to $100 \mu \mathrm{M}$ of $\mathrm{H}_{2} \mathrm{O}_{2}$ treatment for $2 \mathrm{~h}$. Resveratrol obviously reduced $\mathrm{H}_{2} \mathrm{O}_{2}$-induced cell apoptosis and ROS accumulation, and it prevented from $\mathrm{H}_{2} \mathrm{O}_{2}$ induced oxidative stress. Therefore, resveratrol was able to decrease the formation of ROS as well as to protect HLEB-3 cells from apoptosis resulting from $\mathrm{H}_{2} \mathrm{O}_{2}$. Kode et al. (2008) also showed that resveratrol reduced intracellular ROS level. When A549 cells were treated with Cigarette smoke extract (CSE, $1.0 \%, 2.5 \%, 5.0 \%$ ) in the presence or absence of resveratrol $(10 \mu \mathrm{M})$ for $24 \mathrm{~h}$, the ROS level was significantly reduced in all treated with CSE and resveratrol. Resveratrol had an inhibitory effect on senescence process of $100 \mu \mathrm{M}$ of $\mathrm{H}_{2} \mathrm{O}_{2}$ treated in human umbilical vein endothelial cell (HUVEC), and it can recover induction of oxidative-stress in HUVEC cells (Kao et al., 2010). Kim et al. (2012) reported when A549 and HeLa cells exposed with $100 \mathrm{nM}$ of phobol 12-myristate 13-acetate (PMA) were treated for $24 \mathrm{~h}$ with $10 \mu \mathrm{M}$ of resveratrol, $100 \mathrm{nM}$ PMA increased ROS generation up to 5.5- and 4.2-fold in A549 and $\mathrm{HeLa}$ cells, respectively, and $10 \mu \mathrm{M}$ resveratrol suppressed PMA-induced ROS production by $36 \%$ and $35.8 \%$ in A549 and HeLa cells, respectively. Some studies have been shown that treatment with resveratrol ( 0.5 and 10 $\mu \mathrm{M})$ had no effect on production of ROS. There were no significant differences in ROS generation between control and Res group $(0.5$ and $10 \mu \mathrm{M})$ in young and senescent 2 hydroxy-4',5'-dimethoxychalcone (HDMC)-induced cells (Mikuła-Pietrasik et al., 2012).

In contrast, other studies have been investigated that resveratrol induced generation of intracellular ROS. 

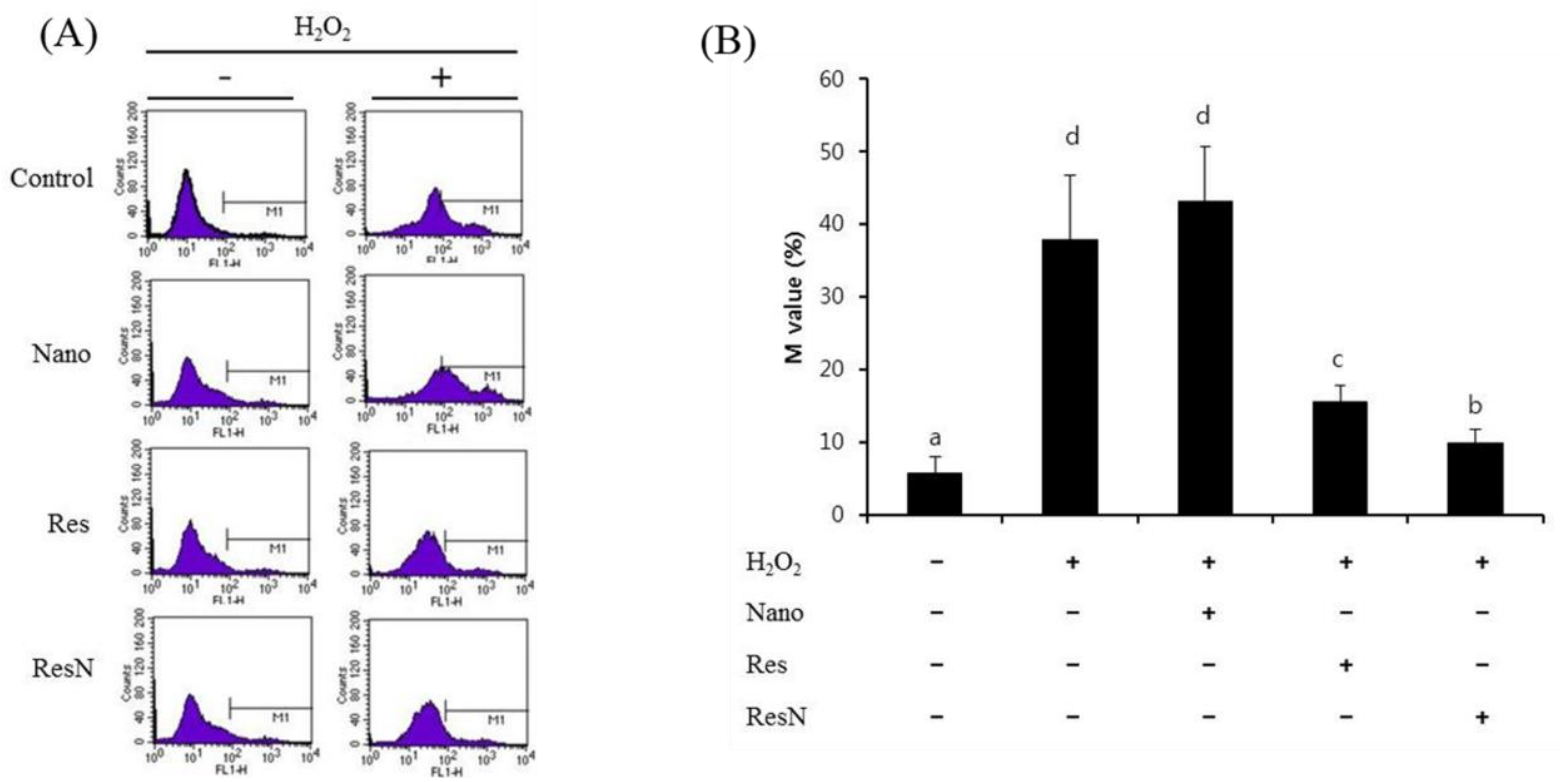

Figure 5. Reactive oxygen species (ROS) inhibition by resveratrol and resveratrol-loaded nanoparticle. (A) A549 cells were pre-treated with control, nanoparticle (Nano), resveratrol (Res, $50 \mu \mathrm{M}$ ) and resveratrol-loaded nanoparticle (ResN) for 4 h, and were post-treated with hydrogen peroxide $(400 \mu \mathrm{M})$ for $8 \mathrm{~h}$. ROS release was determined by oxidized $\mathrm{H}_{2}$ DCFDA (DCF), which is an oxidant-sensitive fluorescent probe. (B) 2',7' Dichlorofluorescein (DCF) at each treatment was measured by FACSCaliur flow cytometry and was analyzed by one-way analysis of variance with least significant difference (LSD) multiple comparison method. The different alphabetical letters between treatments were significantly different at $\mathrm{p}<0.05$.

Intracellular ROS levels were increased significantly when treated with resveratrol $(10 \mu \mathrm{M})$ in HeLa cells at $48 \mathrm{~h}$. Increased intracellular ROS functioned as resveratrolinduced apoptosis in human T-lymphoblastic leukemia cell (CEMC7H2) (Tinhofer et al., 2001), in prostate cancer cells (PC-3 and DU-145) (Shankar et al., 2007). The pro-oxidant activity of resveratrol may act as induction of apoptosis through ROS mediated DNA damages (Nakazato et al., 2005). In treatment with $50 \mu \mathrm{M}$ of resveratrol in human macrophage cell (U937), the ROS levels were rapidly increased at $30 \mathrm{~min}$ incubation, but there were no significant differences from 0.5 to $6 \mathrm{~h}$. The level of Resinduced ROS generation was high at $16 \mathrm{~h}$, but it was decreased at $24 \mathrm{~h}$ (Yaseen, 2011). Also, treatment of 50 and $125 \mu \mathrm{M}$ of resveratrol triggered generation of ROS significantly after $6 \mathrm{~h}$ of treatment in U937 and human breast cancer cell (MCF-7), respectively (Guha et al., 2010). Consequently, resveratrol has been known to have pro- and anti-apoptotic effects through ROS generation, and these effects may be evaluated in different ways in case of cell types, compounds, incubation times and concentrations. It means that many biological processes may exist, and the effects of resveratrol could be dependent on a variety of cellular condition or environment.

\section{Nrf2-Keap1 signaling activated by resveratrol}

The Nrf2-keap1 signaling pathway is the major regulator of cellular protective responses to oxidative stresses caused by ROS and electrophiles (Taguchi et al., 2011; Kansanen et al., 2012; Sporn and Liby, 2012). Nrf2 consists of six highly conserved domains, Neh1-6. Neh1 has a basic leucine zipper motif, which is responsible for DNA binding. Neh2 contains ${ }^{79}$ ETGE $^{82}$ hinge motif and ${ }^{26}$ QDIDLG ${ }^{31}$ latch motif, which are necessary for the interaction with Keap1, and a hydrophilic region of lysine residues, which are required for the Keap1-dependent polyubiquitination and degradation of Nrf2 (Taguchi et al., 2011; Jaramillo and Zhang, 2015). Keap1 consists of five domains. The protein interaction domains, the Broad complex, Tramtrack and Bric-a-Brac (BTB) domain and the Kelch domains, are divided by the intervening region. The BTB domain is responsible for homodimerization of Keap1 and the Kelch domain mediates the interaction with ETGE and DLG motifs in Neh2 domain of Nrf2 (Taguchi et al., 2011; Jaramillo and Zhang, 2015). Keap1 is rich in cysteine residues (27 cysteine residues in human) which can be modified by several antioxidants and electrophiles. This modification leads to conformational changes in the Keap1 disrupting the interaction with $\mathrm{Nrf} 2$ and Keap1, thus inhibiting the polyubiquitination of Nrf2 (Taguchi et al., 2011; Jaramillo and Zhang, 2015). Consequently nondegraded or newly synthesized Nrf2 proteins bypass Keap1, translocate into the nucleus and lead to subsequent target gene expression.

To analyze activation of Nrf2 and Keap1 proteins, A549 
(A)

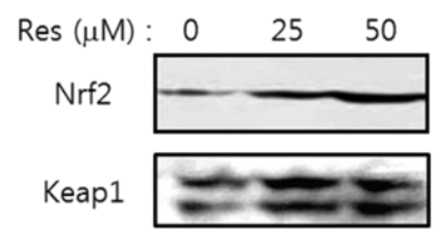

(B)

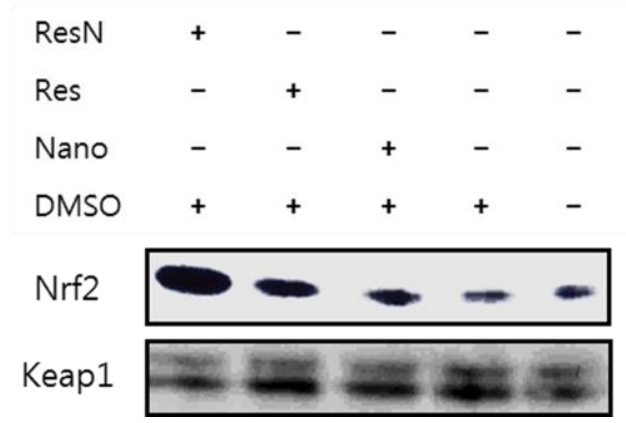

Figure 6. Activation of Nrf2-keap1 signaling pathway caused by resveratrol. Total protein lysates were prepared from A549 cells. Protein lysates $(30 \mu \mathrm{g})$ were resolved by sodium dodecyl sulfate-polyacrylamide gel electrophoresis (SDS-PAGE) and blotted onto nitrocellulose membranes. Nrf2 and Keap1 were detected by immunoblotting analysis. (A) A549 cells were treated with resveratrol (0, 25, and $50 \mu \mathrm{M}$ ) for $60 \mathrm{~min}$. (B) A549 cells were treated with $50 \mu \mathrm{M}$ of resveratrol for $90 \mathrm{~min}$. Dimethyl sulfoxide (DMSO) were used as a solvent for resveratrol. Resveratrol (Res), Nanoparticle (Nano) and resveratrol-loaded nanoparticle (ResN) were used.

cells were treated with resveratrol. Cell lysates were resolved by SDS-PAGE and membranes were probed with antibodies to detect Nrf2 and Keap1. These antibodies detected Nrf2 and Keap1 proteins in A549 cells (Figure 6). The abundance of Nrf2 showed in a dose-dependent manner. Keap1 however, was constant during the treatment (Figure 6A). To validate efficiency for cellular uptake of nanoparticle, resveratrol with or without nanoparticle were treated in A549 cells. Resveratrol-loaded nanoparticle (ResN) showed the highest in Nrf2 abundance (Figure 6B). Collectively, these results indicate that nanoparticle can improve efficiency of resveratrol by increasing the stability of Nrf2 coincident with the inhibition of ubiquitination or degradation caused by Keap1.

\section{CONFLICT OF INTEREST}

We certify that there is no conflict of interest with any financial organization regarding the material discussed in the manuscript.

\section{ACKNOWLEDGMENTS}

This research was carried out with the support of 'High Value-added Food Technology Development Program (314045-03)' funded by Korea Institute of Planning and Evaluation for Technology in Food, Agriculture, Forestry and Fisheries (IPET), Republic of Korea.

\section{REFERENCES}

Aggarwal, B. B., S. Shishodia, C. de la Lastra, I. Villegas, and A. R. Martin. 2006. Resveratrol in Health and Disease. CRC Press, Boca Raton, FL, USA. pp. 33-54.

Beckman, J. S. and W. H. Koppenol. 1996. Nitric oxide, superoxide, and peroxynitrite: the good, the bad, and ugly. Am.
J. Physiol. 271:C1424-1437.

Bravo, L. 1998. Polyphenols: Chemistry, Dietary Sources, Metabolism, and Nutritional Significance. Nutr. Rev. 56:317333.

Chen, L. and M. Subirade. 2005. Chitosan/ $\beta$-lactoglobulin coreshell nanoparticles as nutraceutical carriers. Biomaterals 26:6041-6053.

Cheng, J. C., J. G. Fang, W. F. Chen., B. Zhou., L. Yang, and Z. L. Liu. 2006. Structure-activity relationship studies of resveratrol and its analogues by the reaction kinetics of low density lipoprotein peroxidation. Bioorg. Chem. 34:142-157.

Cockburn, A., R. Bradford, N. Buck, A. Constable, G. Edwards, B. Haber, P. Hepburn, J. Howlett, F. Kampers, C. Klein, M. Radomski, H. Stamm, S. Wijnhoven, and T. Wildemann. 2012. Approaches to the safety assessment of engineered nanomaterials (ENM) in food. Food Chem. Toxicol. 50:22242242.

de la Lastra, C. A. and I. Villegas. 2005. Resveratrol as an antiinflammatory and anti-aging agent: mechanisms and clinical implications. Mol. Nutr. Food Res. 49:405-430.

de la Lastra, C. A. and I. Villegas. 2007. Resveratrol as an antioxidant and pro-oxidant agent: mechanisms and clinical implications. Biochem. Soc. Trans. 35:1156-1160.

Dinkova-Kostova, A. T., W. D. Holtzclaw, R. N. Cole, K. Itoh, N. Wakabayashi, Y. Katoh, M. Yammamoto, and P. Talalay. 2002. Direct evidence that sulfhydryl groups of Keap1 are the sensors regulating induction of phase 2 enzyems that protect against carcinogens and oxidants. Proc. Natl. Acad. Sci. USA 99:11908-11913.

Gracia-Julia, A., M. Rene, M. Cortes-Munoz, L. Picart, T. LopezPedemonte, and D. Chevalier. 2008. Effect of dynamic high pressure on whey protein aggregation: A comparison with the effect of continuous short-time thermal treatments. Food Hydrocoll. 22:1014-1032.

Guha, P., A. Dey, M. V. Dhyani, R. Sen, M. Chatterjee, S. Chattopadhyay, and S. K. Bandyopadhyay. 2010. Calpain and caspase orchestrated death signal to accomplish apoptosis induced by resveratrol and its novel analog hydroxstilbene-1 in cancer cells. J. Pharmacol. Exp. Ther. 334:381-394. 
Ha, H. K., J. W. Kim, M. R. Lee, W. Jun, and W. J. Lee. 2015. Cellular uptake and cytotoxicity of $\beta$-lactoglobulin nanoparticles: The effects of particle size and surface charge. Asian Australas. J. Anim. Sci. 28:420-427.

Hanakova, A., K. Bogdanova, K. Tomankova, S. Binder, R. Bajgar, K. Langova, M. Kolar, J. Mosinger, and H. Kolarova. 2014. Study of photodynamic effects on NIH 3T3 cell line and bacteria. Biomed. Pap. Med. Fac. Univ. Palacky. Olomouc. Czech Repub. 158:201-207.

Herraiz, T. and J. Galisteo. 2004. Endogenous and dietary indoles: a class of antioxidants and radical scavengers in the ABTS assay. Free Radic. Res. 38:323-331.

Hidalgo, I. J., T. J. Raub, and R. T. Borchardt. 1989. Characterization of the human colon carcinoma cell line (Caco-2) as a model system for intestinal epithelial permeability. Gastroenterology 96:736-749.

Hu, B., Y. Ting, X. Zeng, and Q. Huang. 2012. Cellular uptake and cytotoxicity of chitosan-caseinophosphopeptides nanocomplexes loaded with epigallocatechin gallate. Carbohydr. Polym. 89:362-370.

Ignatowicz, E. and W. Baer-Dubowska. 2001. Resveratrol, a natural chemopreventive agent against degenerative diseases. Pol. J. Pharmacol. 53:557-569.

Itoh, K., N. Wakabayashi, Y. Katoh, T. Ishii, K. Igarashi, J. D. Engel, and M. Yamamoto. 1999. Keap1 represses nuclear activation of antioxidant responsive elements by Nrf2 through binding to the amino-terminal Neh2 domain. Genes Dev. 13: 76-86.

Itoh, K., T. Chiba, S. Takahashi, T. Ishii, K. Igarashi, Y. Katoh, T. Oyake, N. Hayashi, K. Satho, I. Hatayama, M. Yamamoto, and Y. Nabeshima. 1997. An Nrf2/small Maf heterodimer mediates the induction of phase II detoxifying enzyme genes through antioxidant response elements. Biochem. Biophys. Res. Commun. 236:313-322.

Jaramillo, M. C. and D. D. Zhang. 2015. The emerging role of the Nrf2-Keap1 signaling pathway in cancer. Genes Dev. 27:21792191.

Kansanen, E., H. K. Jyrkkanen, and A. L. Levonen. 2012 Activation of stress signaling pathways by electrophilic oxidized and nitrated lipids. Free Radic. Biol. Med. 52:973982.

Kao, C. L., L. K. Chen, Y. L. Chang, M. C. Yung, C. C. Hsu, Y. C. Chen, W. L. Lo, S. J. Chen, H. H. Ku, and S. J. Hwang. 2010. Resveratrol protects human endothelium from $\mathrm{H}(2) \mathrm{O}(2)$ induced oxidative stress and senescence via SirT1 activation. J. Atheroscler. Thromb. 17:970-979.

Kim, Y. S., J. W. Sull, and H. J. Sung. 2012. Suppressing effect of resveratrol on the migration and invasion of human metastatic lung and cervical cancer cells. Mol. Biol. Rep. 39:8709-8716.

Livney, Y. D. 2010. Milk proteins as vehicles for bioactives. Curr. Opin. Colloid Interface Sci. 15:73-83.

Mates, J. M., C. Perez-Gomez, and I. N. Castro. 1999. Antioxidant enzymes and human diseases. Clin. Biochem. 32:595-603.

Mikuła-Pietrasik, J., A. Kuczmarska, M. Kucińska, M. Murias, M. Wierzchowski, M. Winckiewicz, R. Staniszewski, A. Bręborowicz, and K. Książek. 2012. Resveratrol and its synthetic derivatives exert opposite effects on mesothelial celldependent angiogenesis via modulating secretion of VEGF and IL-8/CXCL8. Angiogenesis 15:361-376.
Nakazato, T., K. Ito, Y. Ikeda, and M. Kizaki. 2005. Green tea component, catechin, induces apoptosis of human malignant $\mathrm{B}$ cells via production of reactive oxygen species. Clin. Cancer Res. 11:6040-6049.

Napierska, D., L. C. J. Thomassen, V. Rabolli, D. Lison, L. Gonzalez, M. Kirsch-Volders, J. A. Martens, and P. H. Hoet. 2009. Size-dependent cytotoxicity of monodisperse silica nanoparticles in human endothelial cells. Small 5:846-853.

Ou, B., M. Hampsch-Woodill, and R. L. Prior. 2001. Development and validation of an improved oxygen radical absorbance capacity assay using fluorescein as the fluorescent probe. $\mathrm{J}$. Agric. Food Chem. 49:4619-4626.

Powell, J. J., N. Faria, E. Thomas-McKay, and L. C. Pele. 2010. Origin and fate of dietary nanoparticles and microparticles in the gastrointestinal tract. J. Autoimmun. 34:J226-J233.

Re, R., N. Pellegrini, A. Proteggente, A. Pannala, M. Yang, and C. Rice-Evans. 1999. Antioxidant activity applying an improved ABTS radical cation decolorization assay. Free Radic. Biol. Med. 26:1231-1237.

Renaud, S. and M. de Lorgeril. 1992. Wine, alcohol, platelets, and the French paradox for coronary heart disease. Lancet 339:1523-1526.

SAS Institute Inc. 2003. SAS User's Guide: version 9.1 Cary, NC, USA.

Schieber, M. and N. S. Chandel. 2014. ROS function in redox signaling and oxidative stress. Curr. Biol. 24:R453-R462.

Seeram, N. P., V. V. Kulkarni, and S. Padhye 2006. Sources and chemistry of resveratrol. Resveratrol health and disease. CRC Press, Boca Raton, FL, USA. 17-32.

Shankar, S., I. Siddiqui, and R. K. Srivastava. 2007. Molecular mechanisms of resveratrol (3,4,5-trihydroxy-trans-stilbene) and its interaction with TNF-related apoptosis inducing ligand (TRAIL) in androgen-insensitive prostate cancer cells. Mol. Cell. Biochem. 304:273-285.

Soleas, G. J., E. P. Diamandis, and D. M. Goldberg. 1997. Wine as a biological fluid: history, production, and role in disease prevention. J. Clin. Lab. Anal. 11:287-331.

Sporn, M. B. and K. T. liby. 2012. NRF2 and cancer: the good, the bad and the importance of context. Nat. Rev. Cancer 12:564571.

Taguchi, K., H. Motohashi, and M. Yamamoto. 2011. Molecular mechanisms of the Keap1-Nrf2 pathway in stress response and cancer evolution. Genes Cells 16:123-140.

Tinhofer, I., D. Bernhard, M. Senfter, G. Anether, M. Loeffler, G. Kroemer, R. Kofler, A. Csordas, and R. Greil. 2001. Resveratrol, a tumor-suppressive compound from grapes, induces apoptosis via a novel mitochondrial pathway controlled by Bcl-2. FASEB J. 15:1613-1615.

Win, K. Y. and S. S. Feng. 2005. Effects of particle size and surface coating on cellular uptake of polymeric nanoparticles for oral delivery of anticancer drugs. Biomaterials 26:27132722.

Yaseen, A. A. 2011. The Natural Polyphenol Resveratrol Potentiates the Lethality of HDAC Inhibitors in Acutr Myelogenous Leukemia Cells through Multiple Mechanisms. Master's Thesis, Virginia Commonwealth University, Richmond, VA, USA.

Yin, H., H. P. Too, and G. M. Chow. 2005. The effects of particle size and surface coating on the cytotoxicity of nickel ferrite. 
Biomaterials 26:5818-5826.

Zhang, J., X. G. Chen, W. B. Peng, and C. S. Liu. 2008. Uptake of oleoyl-chitosan nanoparticles by A549 cells. Nanomedicine 4:208-214.
Zheng, Y., Y. Liu, J. Ge, X. Wang, L. Liu, Z. Bu, and P. Liu. 2010. Resveratrol protects human lens epithelial cells against $\mathrm{H} 2 \mathrm{O} 2-$ induced oxidative stress by increasing catalase, SOD-1, and HO-1 expression. Mol. Vis. 16:1467-1474. 